\title{
Waste-to-energy: biobutanol production from cellulosic residue of sweet potato by Clostridia acetobutylicum
}

\author{
Yanling Jin ${ }^{1}$, Liang Zhang ${ }^{1,2}$, Zhuolin Yi $^{1}$, Yang Fang ${ }^{1}$, Hai Zhao ${ }^{1^{\dagger}}$ \\ ${ }^{1}$ CAS Key Laboratory of Environmental and Applied Microbiology, Environmental Microbiology Key Laboratory of Sichuan Province, Chengdu Institute \\ of Biology, Chinese Academy of Sciences, Chengdu 610041, China \\ ${ }^{2}$ University of Chinese Academy of Sciences, Beijing, 100049, China
}

\begin{abstract}
Biobutanol has been emerging as a renewable replacement to overcome fossil fuel limit due to its attractive qualities. The waste resources utilization is an economically feasible and eco-friendly way to produce biobutanol. In this work, the potential of butanol fermentation with sweet potato residue (SPR) obtained from ethanol fermentation was evaluated. To assist sugar release for butanol production by Clostridia acetobutylicum, a pretreatment approach with dilute sulfuric acid was established via response surface methodology. The maximum butanol concentration of $3.77 \mathrm{~g} / \mathrm{L}$ was obtained at the optimal conditions of pretreatment at $1 \%(\mathrm{v} / \mathrm{v})$ dilute sulfuric acid, and $115^{\circ} \mathrm{C}$ for 30 min. Detoxifying the hydrolysate with XAD-4 resin significantly enhanced butanol fermentation performance, while adding nutritional supplements had no significant influence. The stability of the fermentation process was verified by the $2 \mathrm{~L}$-scale of fermentation, resulting in $7.96 \mathrm{~g} / \mathrm{L}$ of butanol, $13.42 \mathrm{~g} / \mathrm{L} \mathrm{h}$ of Acetone-Butanol-Ethanol (ABE), and $0.34 \mathrm{~g} / \mathrm{g}$ of ABE yield, respectively. This study demonstrates a bio-refinery strategy of conversion from waste biomass to energy, confirms the feasibility of utilizing the cost saving SPR as feedstock to produce butanol through fermentation, and provides a novel approach for minimization of environmental pollution.
\end{abstract}

Keywords: Biobutanol, Clostridia acetobutylicum, Sweet potato residue, Resources recovery

\section{Introduction}

Currently, oil, coal and gas still account for most of primary energy consumption [1]. However, due to the limited supply of fossil fuels, the increasing and fluctuating price of gasoline and environmental concerns brought by greenhouse gas emissions, there has been an increased interest in looking for green and sustainable energy [2]. Liquid fuel derived from biomass provides an opportunity for nations to replace fossil fuel in transportation sector, increase energy independency and reduce greenhouse gas emissions, because the employed raw material is renewable and widespread [3, 4].

Among the biomass derived liquid fuels, butanol is superior to ethanol, considering its more hydrophobic property, higher energy density, better anti-corrosive property, compatibility with existing transportation pipeline infrastructures, and can be mixed with gasoline at any ratio [5]. Global demand for butanol keeps on raising, and the market size of butanol is estimated at USD 4.0 billion by 2025 [6]. However, current commercial biobutanol is mainly produced from starch or sugar based crops, which is called first-generation biobutanol. Considering the cost, first-generation biobutanol is not competitive with fossil fuels because of expensive feedstock [7, 8]. Therefore, availability of suitable and cheap raw materials is one of the key factors for the industrialization of biobutanol production. At the same time, there are huge quantities of biogenic waste and residue all around the world. Minimizing or eliminating waste is a common pressure faced by all countries. Therefore, biobutanol production from waste biomass can reduce production costs and has environmental benefits, which is also known as the second-generation biobutanol.

China is the biggest sweet potato producer, with an annual yield of about 100 million tons [9], and almost $50 \%$ of sweet potato is processed into varieties of products such as ethanol. Sweet potato is an attractive raw material for bioethanol production [10, 11]. After fermentation, most of starch and soluble sugars in sweet potato are converted to ethanol by Saccharomyces cerevisiae, leaving a large amount of residue as environmental pollutant. The main
This is an Open Access article distributed under the terms of the Creative Commons Attribution Non-Commercial License (http://creativecommons.org/licenses/by-nc/3.0/) which permits unrestricted non-commercial use, distribution, and reproduction in any medium, provided the original work is properly cited.

Copyright (C) 2022 Korean Society of Environmental Engineers
Received August 11, 2021 Accepted October 20, 2021

${ }^{\dagger}$ Corresponding author

E-mail: zhaohai@cib.ac.cn

Tel: +86-28-82890725 Fax: +86-28-82890733

ORCID: 0000-0002-6116-6149 
components in the sweet potato residue (SPR) are cellulose, residual sugar and protein. Although the carbohydrates in SPR cannot be used by Saccharomyces cerevisiae to keep on producing ethanol, they can be utilized via Acetone-Butanol-Ethanol (ABE) fermentation by clostridia to produce butanol. However, to the best of our knowledge, there is no research reported on biobutanol production from SPR. When SPR was used to produce biobutanol, sweet potato could be converted to bioethanol and biobutanol step by step in an integrated bio-refinery manner to maximize the economic value of the feedstock while reduce the waste streams produced.

The existed clostridia strains are not able to efficiently hydrolyze non-starch polysaccharides and cellulose-rich residues. Residues must be hydrolyzed to simple sugars for butanol fermentation using physical-chemical pretreatment and/or enzymatic hydrolysis [12]. Pretreatment is one of the most costly steps among the whole process of conversion from biomass into biobased products, so the lower-cost and effective pretreatment approaches are strongly encouraged [13]. Although a variety of methods has been developed for the pretreatment of cellulosic biomass, dilute sulphuric acid pretreatment is still the most widely used and profitable method [14]. Unfortunately, besides sugars, various microbial inhibitors are generated during acid hydrolysis such as furfural, 5-hydroxymethyl furfural, acetic acid, formic acid, ferulic acid, coumaric acid, syringaldehyde and vanillin $[15,16]$. The toxicity of inhibitors in hydrolysate is a major obstacle to the following butanol fermentation. To ensure the vitality of the fermentation microorganisms and to have high-performance fermentation, removing the inhibitors by detoxification is necessary.

Therefore, the main objective of this work is to develop an novel approach for biobutanol production using the residue generated from bioethanol fermentation of sweet potato in an integrated bio-refinery concept to improve the overall efficiency of biomass utilization and ultimately reduce the waste stream. Specifically, this paper will optimize pretreatment process, overcome fermentation inhibition and investigate the effects of dilute sulphuric acid pretreatment, detoxification methods as well as nutrients supplementation on biobutanol fermentation performance of Clostridia acetobutylicum CICC 8012.

\section{Material and Methods}

\subsection{Microorganism Strain and Inoculum Development}

Clostridia acetobutylicum strain CICC 8012 was purchased from China Center of Industrial Culture Collection (CICC). The freeze-dried cultures were rejuvenated according to CICC's instructions. Activated spores which were ready for inoculum development were maintained in sterile corn medium (50 g corn powder per liter) and stored under anaerobic conditions at $4^{\circ} \mathrm{C}$. Before fermentation, spores were heated at $100^{\circ} \mathrm{C}$ for $90 \mathrm{~s}$, and vegetative cells were grown anaerobically in corn medium at $37^{\circ} \mathrm{C}$ for $24 \mathrm{~h}$.

\subsection{Characterization of the SPR}

SPR were collected from an industrial plant with capacity of 10,000 tons ethanol per year [11]. Fresh SPR was dried and milled using a high-speed pulverizer (JP-300A; JIUPIN Industry and Trade Co.,
China). Cellulose content was determined by the acetic/nitric reagent extraction method [17]. Total residual sugar was determined by HPLC (ELSD 6000; All-tech. corp., CA) using an Aminex HPX-87-Pb column (Bio-Rad, Hercules, USA) at $80^{\circ} \mathrm{C}$ and flow rate of $0.6 \mathrm{ml} / \mathrm{min}$ with distilled water as eluent. Nitrogen gas was used as carrier at the pressure of $2.8 \mathrm{Bar}$ and draft temperature was $105^{\circ} \mathrm{C}$ for the ELSD detector [11, 19]. Protein content was determined by the Kjeldahl method [18]. The ash content of lignin was determined gravimetrically in a muffle furnace at $550^{\circ} \mathrm{C}$ for $4 \mathrm{~h}$. The sample was digested in a mixture of nitric and perchloric acids $(5+1, \mathrm{v} / \mathrm{v})$ and analyzed for $\mathrm{Na}, \mathrm{K}, \mathrm{Ca}, \mathrm{Mg}, \mathrm{P}, \mathrm{Cu}, \mathrm{Mn}, \mathrm{Zn}$ and Fe using inductively coupled plasma atomic emission spectrometer (ICP-AES, IRIS 1000).

\subsection{Pretreatment of the SPR}

As pretreatment for enzymatic hydrolysis, every $100 \mathrm{~g}$ of SPR was suspended in $0.9 \mathrm{~L}$ of dilute sulfuric acid. The central composite design (CCD) with response surface methodology (RSM) was used to investigate the effects of pretreatment conditions on butanol production. Based on preliminary single factor experiments, dilute sulphuric acid concentration (A), thermal treatment temperature (B) and thermal treatment time (C) were chosen as factors (independent variables) and final butanol concentration as response variable (dependent variable). In this experimental design, there were 3 coded factor levels: $-1,0,+1$; in which -1 corresponds to the low level of each factor, 0 to the mid-level, and +1 to the high level. The levels were settled down as A $(0.5,1.0,1.5 \%$, $\mathrm{v} / \mathrm{v}), \mathrm{B}\left(110,115,120^{\circ} \mathrm{C}\right)$, and $\mathrm{C}(15,30,45 \mathrm{~min})$.

\subsection{Enzymatic Hydrolysis of the SPR}

The pretreated mixture was cooled to room temperature, and the $\mathrm{pH}$ was adjusted to 4.8 using $\mathrm{Ca}(\mathrm{OH})_{2}$. Subsequently, $1 \mathrm{~mL}$ of cellulase and $1 \mathrm{ml}$ of xylanase were added to $1 \mathrm{~L}$ of the mixture. After this, the mixture was incubated at $50^{\circ} \mathrm{C}$ for 48 h. Finally, the mixture was centrifuged at 5,000 $\mathrm{g}$ for $5 \mathrm{~min}$ to remove sediment. The cellulose (GC220, DuPont ${ }^{\mathrm{TM}}$ Genencor ( S Science) had a declared activity of $89 \mathrm{FPU} / \mathrm{mL}, 184 \mathrm{mg}$ protein/mL. The xylanase (Multifect, DuPont ${ }^{\mathrm{TM}}$ Genencor ${ }^{\circledR}$ Science) had a declared activity of $8,000 \mathrm{GXU} / \mathrm{mL}, 47 \mathrm{mg}$ protein $/ \mathrm{ml}$. GXU is based on the release of Remazol Brilliant Blue-dyed birch wood xylan at $\mathrm{pH} 4.5$ and $30^{\circ} \mathrm{C}$ in $10 \mathrm{~min}$, using a xylanase reference standard [19].

\subsection{Detoxification of the Hydrolysate}

\subsubsection{Over-liming}

Over-liming was carried out by adding $\mathrm{Ca}(\mathrm{OH})_{2}$ to increase the $\mathrm{pH}$ of hydrolysate to 10 . After $1 \mathrm{~h}$, the hydrolysate was centrifuged to remove the sediment, and then $\mathrm{H}_{2} \mathrm{SO}_{4}$ was added to reach $\mathrm{pH}$ $6.8 \pm 0.2$, suitable for biobutanol production. A precipitate formation was observed, which was eliminated by filtration [20-22].

\subsubsection{Activated charcoal adsorption}

Every $25 \mathrm{~g}$ of activated charcoal was added to $1 \mathrm{~L}$ hydrolysate, and the mixture was agitated at $150 \mathrm{rpm}, 45^{\circ} \mathrm{C}$ for $60 \mathrm{~min}$. Finally, the activated charcoal was removed by centrifugation at 1,100 g for $15 \mathrm{~min}$ [23]. 


\subsubsection{XAD-4 Resin Adsorption}

Water was first pumped through XAD-4 resin (Sigma-Aldrich, France) in a glass column (internal diameter, $2 \mathrm{~cm}$; height, 20 $\mathrm{cm})$, followed by the hydrolysate [24].

\subsection{Batch Fermentation}

The detoxified hydrolysate was used as a fermentation medium. Unless otherwise specified, no extra nutrients were added to the medium, and fermentation was performed in $200 \mathrm{~mL}$ screw-capped bottles with $100 \mathrm{~mL}$ fermentation medium. All the media were purged with $\mathrm{N}_{2}$ to remove $\mathrm{O}_{2}$. In all experiments, $5 \mathrm{~mL}$ of high motile cells of $C$. acetobutylicum CICC 8012 was inoculated and the temperature was maintained at $37^{\circ} \mathrm{C}$. There was no agitation or $\mathrm{pH}$ control. During fermentation, $2 \mathrm{~mL}$ of samples were withdrawn for $\mathrm{ABE}$ and sugar analysis at $12 \mathrm{~h}$ intervals. Before analysis, the samples were centrifuged at $10,000 \mathrm{~g}$ for $2 \mathrm{~min}$.

\subsection{Determination of Sugars and ABE Concentrations}

The carbohydrate compositions of SPR were also determined by HPLC (ELSD 6000; All-tech. corp., CA) as described in section 2.2. ABE concentration was determined by gas chromatography (FULI 9790; FULI Corp., China) fitted with a flame ionization detector (FID) under the following condition: a GDX-103 column (FULI Corp., China); temperature of injector and detector, $200^{\circ} \mathrm{C}$; temperature of column oven, $180^{\circ} \mathrm{C}$; nitrogen carrier gas flow rate, $30 \mathrm{ml} / \mathrm{min}$. ABE yield was calculated using Eq. (1) [25].Fermentation efficiency was calculated using Eq. (2) [26].

$$
\begin{gathered}
A B E \text { yield }(\mathrm{g} / \mathrm{g})=\frac{\text { Total } A B E \text { produced }}{\text { Total sugar utilized }} \\
\text { Fermentation efficiency }(\%)=\frac{\text { Actual yield }}{\text { Theoretical yield }} \times 100 \%
\end{gathered}
$$

\subsection{Morphological Observation of SPR Using Scanning Electron Microscopy (SEM)}

The morphology of the SPR was investigated using a ZEISS Gemini SEM 300 microscope (Carl Zeiss NTS GmbH, Germany) equipped with a Schottky Field Emission Gun (FEG). All samples were deposited on adhesive carbon tape and sputtered by a DESK IVTM sputter unit (Denton Vacuum Inc., NJ, S.A.) equipped with $\mathrm{Au} / \mathrm{Pd}$ target.

\subsection{Statistical Analysis}

Each experiment was conducted in triplicate, and the data were recorded as the mean. The CCD design and RSM values were processed used Design-Expert 12.0 software (Stat-Ease, USA). Significant differences between samples were evaluated using SPSS 19.0 software.

\section{Results and Discussion}

\subsection{Composition of SPR}

The main composition of SPR is cellulose (40.42\%), which is not able to be hydrolyzed by the gentle pretreatment and enzymatic hydrolysis in the previous ethanol production process. It should be noted that the residual sugar content in SPR was high (13.01\%). The residual sugars mainly consisted of oligosaccharide or pentose, which are not able to be metabolized by Saccharomyces cerevisiae to keep on producing ethanol [11]. Interestingly, there was $16.49 \%$ of protein in SPR. That maybe due to high protein accumulation in $S$. cerevisiae [27]. S. cerevisiae is known as the most widely used eukaryotic microorganism for single cell protein production under aerobic condition. Although oxygen is an important factor in $S$. cerevisiae growth, the maximum specific growth rate of $S$. cerevisiae is similar under aerobic and anaerobic conditions [27, 28]. Therefore, the previous anaerobic fermentation of ethanol production also resulted in high content of protein in SPR. There was $14.54 \%$ of ashes in SPR, and $\mathrm{Na}, \mathrm{K}, \mathrm{Ca}, \mathrm{Mg}, \mathrm{P}, \mathrm{Cu}, \mathrm{Mn}, \mathrm{Zn}$ and $\mathrm{Fe}$ in the SPR were 1274, 4321, 876, 586, 1489, 10.1, 15.2, 6.9 and $49.1(\mathrm{mg} / \mathrm{kg})$, respectively.

\subsection{Effect of Dilute Sulfuric Acid Pretreatment on ABE Fermentation}

3.2.1. Statistical analysis and model fitting using CCD-RSM

Although the microbial inhibitors are unavoidably generated during acid hydrolysis, dilute sulphuric acid pretreatment is still the most widely used approach for hydrolysis of lignocellulosic biomass $[14,29] . \mathrm{H}^{+}$concentration directly affects the hydrolysis efficiency of the carbohydrate polymers [30]. Acid pretreatment can be carried out with either a high acid concentration at low temperatures or a low acid concentration at high temperatures [13]. In addition, residence time for thermal treatment directly affects the production cost. Therefore, the effects of and thermal treatment time on ABE fermentation were investigated. The significant pretreatment parameters, including concentration of dilute sulphuric acid, thermal treatment temperature and thermal treatment time, were optimized using CCD. The experimental data (Table 1) were fitted to quadratic models, and the quadratic regression analysis was carried out using Design-Expert software [31]. The model equation obtained by Design-Expert 12.0 software in terms of code values is as follows:

$$
\begin{gathered}
Y=3.64-0.5123 \mathrm{~A}-0.4061 \mathrm{~B}-0.0722 \mathrm{C}+0.0200 \mathrm{AB}- \\
0.0503 \mathrm{AC}-0.0435 \mathrm{BC}-0.9319 \mathrm{~A}^{2}-1.08 \mathrm{~B}^{2}-0.3394 \mathrm{C}^{2}
\end{gathered}
$$

Where $Y$ represents butanol concentration, $\mathrm{A}=$ concentration of dilute sulphuric acid, $\mathrm{B}=$ thermal treatment temperature, and $\mathrm{C}=$ thermal treatment time.

The model was analyzed by analysis of variance (ANOVA) and the results were shown in Table 2. F-test and $P$-value were used to check the statistical significance of each coefficient in the regression model. The F-value of the model was calculated by dividing the mean square of the model by the mean square of the residuals [32]. A large $\mathrm{F}$ value (79.92) with a small $P$ value $(p<0.0001)$ indicated that the model was statistically significant. In Table 2 , linear coefficients (A and B) and quadratic coefficients $\left(\mathrm{A}^{2}, \mathrm{~B}^{2}\right.$, and $C^{2}$ ) were significant model terms $(p<0.05)$, indicating these factors were quite important to the butanol fermentation. The lack of fit is a measure of the failure of the model to fit the empirical data and the model should be discarded if the lack of fit was 
Table 1. CCD Experimental Sets and Corresponding Response

\begin{tabular}{lcccc}
\hline Run & Factor A Concentration (\%,v/v) & Factor B Temperature $\left({ }^{\circ} \mathbf{C}\right)$ & Factor C Time $(\mathbf{m i n})$ & Response Butanol $(\mathbf{g} / \mathbf{L})$ \\
\hline 1 & 1.0 & 115 & 30 & 3.76 \\
2 & 0.5 & 120 & 45 & 3.41 \\
3 & 1.0 & 120 & 30 & 1.88 \\
4 & 0.5 & 115 & 30 & 3.08 \\
5 & 1.0 & 115 & 15 & 3.13 \\
6 & 1.0 & 115 & 45 & 3.19 \\
7 & 1.0 & 115 & 30 & 3.88 \\
8 & 1.0 & 115 & 30 & 2.95 \\
9 & 1.0 & 110 & 15 & 0.70 \\
10 & 1.5 & 120 & 30 & 3.55 \\
11 & 1.0 & 115 & 45 & 2.18 \\
12 & 0.5 & 110 & 45 & 1.11 \\
13 & 1.5 & 110 & 15 & 1.49 \\
14 & 0.5 & 120 & 30 & 3.74 \\
15 & 1.0 & 115 & 30 & 2.05 \\
16 & 1.5 & 115 & 30 & 3.78 \\
17 & 1.0 & 115 & 15 & 1.23 \\
18 & 1.5 & 110 & 45 & 0.22 \\
19 & 1.5 & 120 & 15 & 2.29 \\
20 & 0.5 & 110 & & \\
\end{tabular}

Table 2. Analysis of Variance of Response Surface Quadratic Model

\begin{tabular}{|c|c|c|c|c|c|c|}
\hline Source & Sum of Squares & df & Mean Square & F-value & p-value & Remarks \\
\hline Model & 25.29 & 9 & 2.81 & 79.92 & $<0.0001$ & significant \\
\hline A-Concentration & 2.62 & 1 & 2.62 & 74.66 & $<0.0001$ & \\
\hline B-Temperature & 1.65 & 1 & 1.65 & 46.92 & $<0.0001$ & \\
\hline C-Time & 0.0521 & 1 & 0.0521 & 1.48 & 0.2513 & \\
\hline $\mathrm{AB}$ & 0.0032 & 1 & 0.0032 & 0.091 & 0.769 & \\
\hline AC & 0.0202 & 1 & 0.0202 & 0.5747 & 0.4659 & \\
\hline $\mathrm{BC}$ & 0.0151 & 1 & 0.0151 & 0.4306 & 0.5265 & \\
\hline $\mathrm{A}^{2}$ & 2.39 & 1 & 2.39 & 67.94 & $<0.0001$ & \\
\hline $\mathrm{B}^{2}$ & 3.22 & 1 & 3.22 & 91.57 & $<0.0001$ & \\
\hline $\mathrm{C}^{2}$ & 0.3168 & 1 & 0.3168 & 9.01 & 0.0133 & \\
\hline Residual & 0.3515 & 10 & 0.0352 & & & \\
\hline Lack of Fit & 0.2922 & 5 & 0.0584 & 4.92 & 0.0526 & not significant \\
\hline Pure Error & 0.0594 & 5 & 0.0119 & & & \\
\hline Cor Total & 25.64 & 19 & & & & \\
\hline $\mathrm{R}^{2}$ & 0.9863 & & & & & \\
\hline Adjusted $\mathrm{R}^{2}$ & 0.9739 & & & & & \\
\hline Predicted $\mathrm{R}^{2}$ & 0.9253 & & & & & \\
\hline
\end{tabular}

significant [32]. In this case, the value of "the lack of fit" was not significant $(p=0.0526>0.05)$, representing that the lack of fit was not significant relative to the pure error and the regression model fitted the data properly. The determination coefficient $\left(\mathrm{R}^{2}\right.$ $=0.9863$ ) was close to 1 , which indicated that $98.63 \%$ of real pretreatment effects could be explained under the range of experimental variables. The predicted $R^{2}(0.9253)$ were in reasonable agreement with the adjusted $R^{2}(0.9739)$, which represented that the observed experimental data had a high degree of correlation with the predicted values and the regression equation can be used to analyze and predict the experimental results.

\subsubsection{Analysis of response surface plots}

Adequacy of the model was further assessed by probability plot (Fig. 1(a)). All data points followed along straight line of regression indicating that a good correlation was given between the predicted 

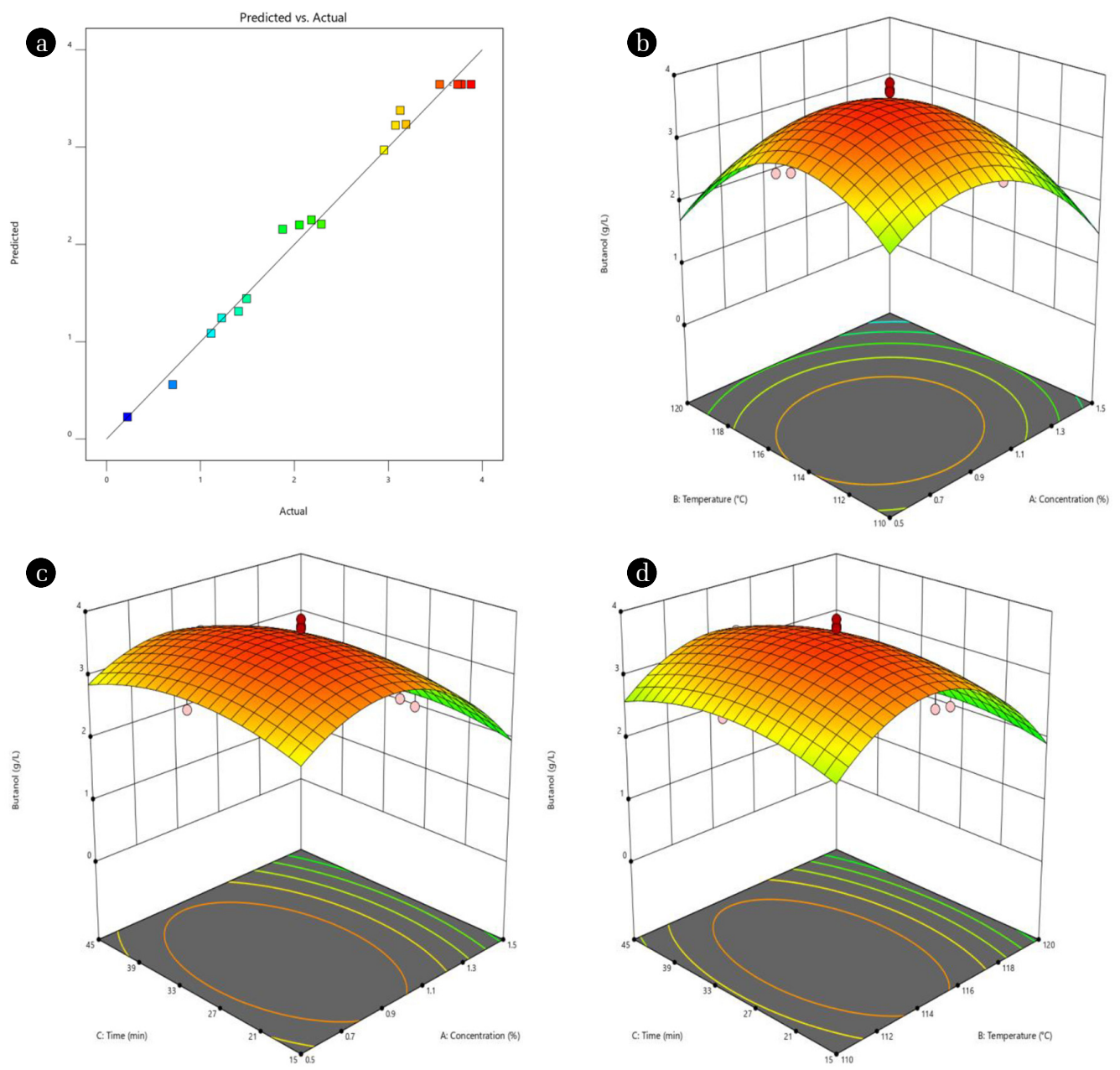

Fig. 1. Surface response plots of the factor's effect on butanol fermentation: (a) the correlation plot of predicted values vs. experimental measurements for butanol concentration, (b) interactive effects of dilute sulfuric acid concentration and thermal treatment temperature, (c) interactive effects of dilute sulfuric acid concentration and thermal treatment time, and (d) interactive effects of thermal treatment temperature and thermal treatment time.

and experimental butanol concentration under dilute sulfuric acid pretreatment. To elucidate the interactive effects between the various pretreatment parameters on the final butanol concentration, the three-dimensional (3D) surface plots were generated (Fig. 1(b) (d)). Concentration of dilute sulfuric acid and thermal treatment temperature presented the most important factors $(p<0.0001)$, affecting the final butanol concentration effectively, which was consistent with the results of ANOVA analysis for the model. Interaction between dilute sulfuric acid concentration and thermal treatment temperature exhibited a steeper response surface than interactions between other independent factors (Fig. 1(b)). As shown in Fig. 1(b) and 1(c), the butanol concentration increased first and then decreased with increasing dilute sulfuric acid concentration when heat-treated was at constant temperature and time. The influence of thermal treatment temperature on the final butanol concentration showed a similar trend to dilute sulfuric acid concentration (Fig. 1(b) and 1(d)). These results indicate that the dilute sulfuric acid concentration and thermal treatment temperature are not the higher the better, which maybe due to the inhibitors generated under the high $\mathrm{H}+$ concentration at high temperature. Fig. 1(c) and 1(d) showed that thermal treatment time had no significant influence on the final butanol concentration $(p=0.2513>0.05)$.

\subsubsection{Model Verification}

From the model, the final optimal pretreatment parameters were predicted as: $1.0 \%(\mathrm{v} / \mathrm{v})$ dilute sulfuric acid, and thermal treatment at $115^{\circ} \mathrm{C}$ for $30 \mathrm{~min}$, under which the predicted butanol concentration was $3.64 \mathrm{~g} / \mathrm{L}$. Therefore, experiments were set up at the optimum predicted criteria for validating the optimization. Under the optimal pretreatment conditions, final butanol concentration was $3.77 \mathrm{~g} / \mathrm{L}$ (Fig. 2(a)), which was close to the predicted value. The good correlation between the experimental data and predicted values confirmed that the predicted model was adequately accurate for predicting the final butanol concentration.

Under the optimal pretreatment conditions, the sugars obtained from acidically hydrolyzed SPR were as follows: $4.11 \mathrm{~g} / \mathrm{L}$ of glucose, 

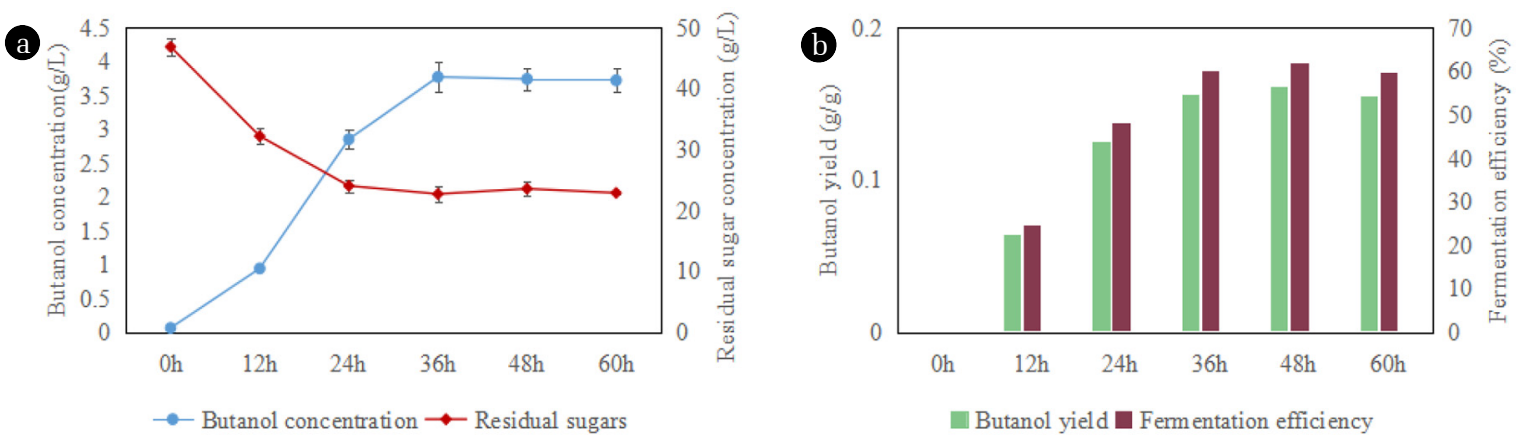

Fig. 2. Butanol fermentation profiles under optimal pretreatment conditions: (a) butanol and residual sugars concentration and (b) butanol yield and fermentation efficiency.
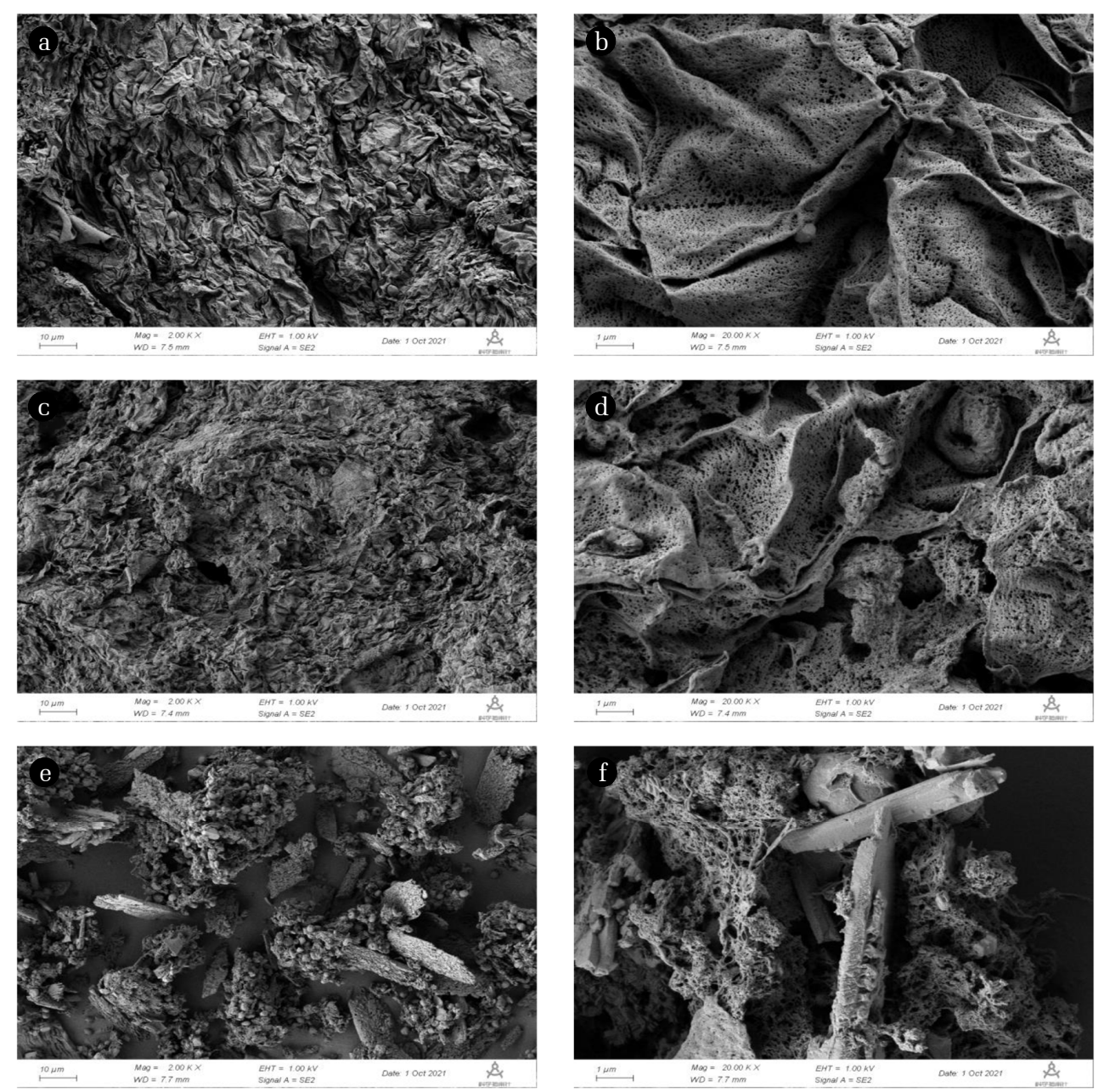

Fig. 3. SEM images of SPR: (a) fresh SPR $(2,000 \times)$, (b) fresh SPR $(20,000 \times)$, (c) pre-treated SPR $(2,000 \times)$, (d) pre-treated SPR $(20,000 \times)$, (e) enzymatically hydrolysed SPR $(2,000 \times)$, and (f) enzymatically hydrolysed SPR $(20,000 \times)$

$10.30 \mathrm{~g} / \mathrm{L}$ of xylose, $1.47 \mathrm{~g} / \mathrm{L}$ of galactose, $1.32 \mathrm{~g} / \mathrm{L}$ of arabinose, $1.67 \mathrm{~g} / \mathrm{L}$ of mannose, and $0.36 \mathrm{~g} / \mathrm{L}$ of cellobiose, resulting in the total sugar concentration of $19.23 \mathrm{~g} / \mathrm{L}$. After acidic hydrolysis, the sugars obtained from enzymatically hydrolyzed SPR were as follows: $22.86 \mathrm{~g} / \mathrm{L}$ of glucose, $14.71 \mathrm{~g} / \mathrm{L}$ of xylose, $2.07 \mathrm{~g} / \mathrm{L}$ of galactose,
$1.84 \mathrm{~g} / \mathrm{L}$ of arabinose, $2.38 \mathrm{~g} / \mathrm{L}$ of mannose, and $2.98 \mathrm{~g} / \mathrm{L}$ of cellobiose, resulting in the total sugar concentration of $46.84 \mathrm{~g} / \mathrm{L}$, which increased to 2.44 times as compared with that in acidic hydrolysate. Furthermore, sugar release was consistent with the surface morphology of fresh SPR, pre-treated SPR and enzymatically hydrolysed 
SPR. As shown in Fig. 3, both high and low magnifications showed the gradual degradation of SPR, and the effect of enzymatic hydrolysis on morphology was stronger than that of acidic hydrolysis. The fresh SPR showed a relatively compact and rigid surface before dilute sulphuric acid pretreatment. After acidic hydrolysis, it exhibited a corrugated and more porous surface. The enzymatically hydrolysed SPR showed a fragmentized structure, revealing the disruption of tissue network and the degradation of SPR.

However, according to the fermentation profiles (Fig. 2), ABE fermentation almost stopped at $36 \mathrm{~h}$, while the residual sugar was still as high as $24.02 \mathrm{~g} / \mathrm{L}$, indicating not all released sugars were fermented by $C$. acetobutylicum CICC 8012 . In addition, butanol yield is only $0.16 \mathrm{~g} / \mathrm{g}$, and fermentation efficiency is only about 60\%. The poor performance of $C$. acetobutylicum CICC 8012 during fermentation from SPR hydrolysate was attributed to by-products of hydrolysis generated by dilute sulfuric acid pretreatment [33]. Jonglertjunya et al. [34] found that only $0.27 \mathrm{~g} / \mathrm{L}$ of butanol could be obtained by Clostridium beijerinckii (TISTR 1461) from un-detoxified sugarcane bagasse hydrolysate. Luo et al. [35] found that butanol yield is only $0.08 \mathrm{~g} / \mathrm{g}$ in the $\mathrm{ABE}$ fermentation from un-detoxified corncob hydrolysate. Although the dilute acid pretreatment commonly results in low concentrations of inhibitory compounds [36], we also have to consider the by-products produced in SPR from the last round of ethanol fermentation, which may inhibit the next round of $\mathrm{ABE}$ fermentation. Therefore, detoxification of hydrolysate is necessary.

\subsection{Effect of Different Detoxification Approaches on ABE Fermentation}

There are diverse of feedstock including wastes and residues of agriculture and industry have been reported for ABE production. Nearly all ABE fermentation from residues consists of following steps: pretreatment, hydrolysis and detoxification. In order to remove the inhibitory compounds in the SPR hydrolysate, effects of $\mathrm{Ca}(\mathrm{OH})_{2}$ over-liming, activated charcoal adsorption and XAD-4 resin absorption on $\mathrm{ABE}$ fermentation were investigated.

As shown in Table 3, three detoxification approaches resulted in varied amount of $\mathrm{ABE}$ solvents. During $72 \mathrm{~h}$ of fermentation, $3.72 \mathrm{~g} / \mathrm{L}$ of butanol and $6.21 \mathrm{~g} / \mathrm{L}$ of $\mathrm{ABE}$ were produced in un-detoxified group, resulting in butanol yield and ABE yields were only $0.16 \mathrm{~g} / \mathrm{g}$ and $0.26 \mathrm{~g} / \mathrm{g}$, respectively. As compared to un-detoxified hydrolysate, C. acetobutylicum CICC 8012 exhibited significantly better fermentation performance in detoxified hydrolysates, and ABE yield increased to $0.28 \mathrm{~g} / \mathrm{g} \sim 0.35 \mathrm{~g} / \mathrm{g}$. However, detoxification treatment inevitably led to more or less sugar loss. After being detoxified by $\mathrm{Ca}(\mathrm{OH})_{2}$ over-liming, total sugar concentration in the hydrolysate decreased to $33.03 \mathrm{~g} / \mathrm{L}$, resulting in $29.49 \%$ of sugar loss. The over-liming process has been reported as an effective method for detoxification of various hydrolysates such as: bagasse, wood and barley straw [37-39]. Sugar loss was recently reported as a major drawback of over-liming due to hydroxide-catalyzed degradation reactions and conversion of sugars to unfermentable compounds [40]. XAD-4 resin detoxification led to the lowest sugar loss with a total sugar concentration of $44.51 \mathrm{~g} / \mathrm{L}$, corresponding to $95.03 \%$ of the original concentration. In addition, only $51.22 \%$ of sugars were utilized in un-detoxified group, while $87.01 \%$ of sugars were consumed for $\mathrm{ABE}$ fermentation in the XAD-4 group, corresponding to the lowest final residual sugar concentration, which was in accordance with other papers [12, 41]. Therefore, C. acetobutylicum CICC 8012 showed the best fermentation performance in XAD-4 group, with a $115.59 \%$ improvement in final butanol concentration $(8.02 \mathrm{~g} / \mathrm{L})$ as compared to the un-detoxified group. Furthermore, XAD-4 resin can be easily regenerated and reused to reduce production cost and waste generation. Detoxification strategy should be developed to attain the following objectives: (1) minimal loss of sugars; (2) low energy consumption; (3) limited wastes discharge; and (4) absence of residual metal salts that may inhibit fermentation [42]. XAD-4 resin detoxification can meet all the demands. Therefore, XAD- 4 resin was considered as one of the excellent adsorbents for detoxification of small organic molecules such as furfural, hydroxymethyl furfural, and total phenolic compounds [43].

\subsection{Effect of Additional Nutrients on ABE Fermentation}

Nutrition supplement is necessary to many kinds of waste biomass for butanol fermentation. Yeast extract was supplied as an extra nitrogen source in corn fiber hydrolysate [12]. $\mathrm{KH}_{2} \mathrm{PO}_{4}$ and $\mathrm{MgSO}_{4}$ were added to wheat straw hydrolysate to ensure the successful butanol fermentation [19]. In order to know whether nitrogen source and mineral were the restriction factor for cell growth and butanol production besides hydrolysis inhibitors, nutrition supplement experiments were carried out. According to the basic requirements of $C$. acetobutylicum CICC 8012 for ABE production, $3 \mathrm{~g}$ of soybean meal, $1 \mathrm{~g}$ of $\mathrm{CH}_{3} \mathrm{COONH}_{4}, 0.6 \mathrm{~g}$ of $\mathrm{KH}_{2} \mathrm{PO}_{4}$, and $0.2 \mathrm{~g}$ of $\mathrm{MgSO}_{4}$ were add to $1 \mathrm{~L}$ of medium [19]. Interestingly, the results obtained with the addition of nitrogen source and inorganic salts did not differ significantly from those in the non-addition group $(p>0.05)$. This could be due to the fact that the growth and metabolism requirements of $C$. acetobutylicum CICC 8012 for ABE production were satisfied with the nutrients contained in the SPR as described in section 3.1. The results demonstrated that additional nutrients are not necessary when utilizing SPR as a substrate for ABE pro-

Table 3. ABE Fermentation Parameters under Different Detoxification Processes

\begin{tabular}{lcccc}
\hline Parameters & XAD-4 & Activated charcoal & Over-liming & Untreated \\
\hline Total initial sugar (g/L) & 44.51 & 38.03 & 33.03 & 46.84 \\
Residual sugar (g/L) & 5.78 & 17.11 & 14.71 & 22.85 \\
Butanol concentration (g/L) & 8.02 & 3.45 & 3.53 & 3.72 \\
ABE concentration (g/L) & 13.54 & 5.88 & 6.05 & 6.21 \\
Butanol yield (g/g) & 0.21 & 0.16 & 0.19 & 0.16 \\
ABE yield (g/g) & 0.35 & 0.28 & 0.33 & 0.26 \\
\hline
\end{tabular}


duction, indicating SPR is an attractive option for ABE production as compared with other feedstocks that need nutrition supplement. This advantage makes SPR more economical.

\subsection{Large-scale Fermentation}

Larger-scale fermentation was conducted in a 2-L screw-capped Pyrex bottle with $1 \mathrm{~L}$ XAD-4 resin treated hydrolysate. After fermentation finished, residual sugar concentration, butanol concentration, $\mathrm{ABE}$ concentration, $\mathrm{ABE}$ productivity, and $\mathrm{ABE}$ yield were $6.28 \mathrm{~g} / \mathrm{L}, 7.96 \mathrm{~g} / \mathrm{L}, 13.42 \mathrm{~g} / \mathrm{L}, 0.19 \mathrm{~g} / \mathrm{L} \mathrm{h}$, and $0.35 \mathrm{~g} / \mathrm{g}$, respectively. The results of large-scale fermentation had no statistical significance compared with that of $100 \mathrm{ml}$-scale fermentation $(p>0.05)$. It is reported that $9.3 \mathrm{~g} / \mathrm{L}$ of total $\mathrm{ABE}$ solvents were produced by C. berjerinckii BA101 from corn fiber hydrolysate when treated by sulfuric acid combined with XAD-4 [12], and $3.59 \mathrm{~g} / \mathrm{L}$ of butanol was produced from the XAD-4 treated palm kernel cake [41], which are all lower than those in SPR hydrolysate.

Notably, at the end of fermentation, $38.75 \mathrm{~g} / \mathrm{L}$ of sugars were fermented by C. acetobutylicum CICC 8012, and un-fermented sugars remained in the medium were mainly pentose (Table 4). Almost all glucose and cellobiose were consumed, while $1.94 \mathrm{~g} / \mathrm{L}$ of xylose, $1.36 \mathrm{~g} / \mathrm{L}$ of galactose, $0.87 \mathrm{~g} / \mathrm{L}$ of arabinose and $1.25 \mathrm{~g} / \mathrm{L}$ of mannose couldn't be utilized by C. acetobutylicum CICC 8012 during the fermentation. Although wild clostridia could metabolize pentose by the pentose phosphate pathway, its efficiency is undesired [44]. The recombinant clostridia strains with increased pentose-utilizing ability are to be developed in future work.

Table 4. Sugar Composition in the Hydrolysate at Initial and Final Stages of Fermentation

\begin{tabular}{lcc}
\hline Sugars $(\mathrm{g} / \mathrm{L})$ & Initial stage & Final stage \\
\hline Glucose & 22.45 & 0.57 \\
Xylose & 13.96 & 1.94 \\
Galactose & 1.98 & 1.36 \\
Arabinose & 1.71 & 0.87 \\
Mannose & 2.29 & 1.25 \\
Cellobiose & 2.64 & 0.29 \\
Total sugars & 45.03 & 6.28 \\
\hline
\end{tabular}

\section{Conclusions}

The key issue of the second-generation biobutanol production is to find low-cost feedstocks. This research found a novel way of using SPR as an economical feedstock for biobutanol production. The optimal hydrolysis condition of pretreating SPR with $1 \%(\mathrm{v} / \mathrm{v})$ sulfuric acid at $115^{\circ} \mathrm{C}$ for $30 \mathrm{~min}$ was obtained by CCD-RSM. The key procedure of the overall processes was the further detoxification with XAD-4 resin, which significantly enhanced butanol fermentation performance with a $115.59 \%$ improvement in final butanol concentration as compared to the un-detoxified SPR hydrolysate. Extra nutrients were not necessary when utilizing SPR as a substrate for butanol production. This is the prominent advantage of SPR over other feedstocks that need nutrition supplement. At a $2 \mathrm{~L}$ scale of fermentation, the butanol concentration, ABE concen- tration, ABE yield, and ABE productivity were $7.96 \mathrm{~g} / \mathrm{L}, 13.42 \mathrm{~g} / \mathrm{L}$, $0.35 \mathrm{~g} / \mathrm{g}$ and $0.19 \mathrm{~g} / \mathrm{L} \mathrm{h}$, respectively.

The major highlights in the current study include: (1) This study demonstrates a bio-refinery strategy of conversion from waste biomass to energy. (2) The fermentation results verify the feasibility of utilizing the cost saving SPR as feedstock to produce butanol. (3) Butanol production from SPR provides a novel approach for reducing production cost as well as eliminating environmental pollution brought by waste discharge from bioethanol industry.

\section{Acknowledgment}

This work was supported financially by the National Key R\&D Program of China (Grant No. 2018YFB1501401) and China Agriculture Research System of MOF and MARA (Grant No. CARS-10-B22).

\section{Author Contributions}

Y.J. (Professor) conceived and designed the study, performed the experiments, analyzed the date, and wrote the paper. L.Z. (Ph.D. student) designed and performed the partial experiments. Z.Y. (Associate professor) and Y.F. (Associate professor) reviewed and edited the manuscript. H.Z. (Professor) conceived and designed the study, and acquired funding. All authors read and approved the manuscript.

\section{References}

1. Londono-Pulgarin D, Cardona-Montoya G, Restrepo JC, et al. Fossil or bioenergy? Global fuel market trends. Renew. Sust. Energ. Rev. 2021;143(1):110905.

2. Li G, Chang YX, Chen L, et al. Process design and economic assessment of butanol production from lignocellulosic biomass via chemical looping gasification. Bioresour. Technol. 2020;316: 123906.

3. Sanna A. Advanced Biofuels from Thermochemical Processing of Sustainable Biomass in Europe. Bioenerg. Res. 2012;7(1): 36-47.

4. Waldron KW. Advances in biorefineries : biomass and waste supply chain exploitation. 1st ed. Amsterdam: Woodhead Publishing; 2014. p. 389-390.

5. Karthick C, Nanthagopal K. A comprehensive review on ecological approaches of waste to wealth strategies for production of sustainable biobutanol and its suitability in automotive applications. Energ. Convers. Manage. 2021;239:114219.

6. Lakshmi. n-Butanol Market by Application (Butyl Acrylate, Butyl Acetate, Glycol Ethers, Direct Solvents, Plasticizers), and Region (APAC, North America, Europe, Middle East \& Africa, South America) - Global Forecast to 2025 [Internet]. Narayan: Lakshmi; c2021 [cited 12 August 2021]. Available from: https://www.marketsandmarkets.com/Market-Reports/n-butanol-market-1089.html

7. Li G, Ma SQ, Xue XX, et al. Life cycle water footprint analysis 
for second-generation biobutanol. Bioresour. Technol. 2021;333: 125201.

8. Quiroz-Ramires JJ, Sanchez-Ramirez E, Hernandez-Castro S, et al. Optimal Planning of Feedstock for Butanol Production Considering Economic and Environmental Aspects. Acs Sustain. Chem. Eng. 2017;5:4018-4030.

9. Ding YQ, Jin YL, He KZ, et al. Low Nitrogen Fertilization Alter Rhizosphere Microorganism Community and Improve Sweetpotato Yield in a Nitrogen-Deficient Rocky Soil. Front. Microbiol. 2020;11:678.

10. Zhang L, Chen Q, Jin YL, et al. Energy-saving direct ethanol production from viscosity reduction mash of sweet potato at very high gravity (VHG). Fuel Process. Technol. 2010;91: 1845-1850.

11. Zhang L, Zhao H, Gan MZ, et al. Application of simultaneous saccharification and fermentation (SSF) from viscosity reducing of raw sweet potato for bioethanol production at laboratory, pilot and industrial scales. Bioresour. Technol. 2011;102: 4573-4579.

12. Qureshi N, Ezeji TC, Ebener J, et al. Butanol production by Clostridium beijerinckii. Part I: Use of acid and enzyme hydrolyzed corn fiber. Bioresour. Technol. 2008;99:5915-5922.

13. Hilares RT, Ramos L, da Silva SS, et al. Hydrodynamic cavitation as a strategy to enhance the efficiency of lignocellulosic biomass pretreatment. Crit. Rev. Biotechnol. 2018;38:483-493.

14. Gozan M. Technology selection for rice straw-based second-generation bioethanol production in West Java. Iop. C. Ser. Earth. Env. 2020;599:012095.

15. Okuda N, Soneura M, Ninomiya K, et al. Biological Detoxification of Waste House Wood Hydrolysate Using Ureibacillus thermosphaericus for Bioethanol Production. J. Biosci. Bioeng. 2008;106:128-133.

16. Jönsson LJ, Martín C. Pretreatment of lignocellulose: formation of inhibitory by-products and strategies for minimizing their effects. Bioresour. Technol. 2016;199:103-112.

17. Updegraff DM. Semimicro Determination of Cellulose in Biological Materials. Anal. Biochem. 1969;32:420.

18. Yang T, Rao Z, Xian Z, et al. Economic conversion of spirit-based distillers' grain to 2,3-butanediol by Bacillus amyloliquefaciens. Process Biochem. 2015;50(1):20-23.

19. Jin YL, Fang Y, Huang MJ, et al. Combination of RNA sequencing and metabolite data to elucidate improved toxic compound tolerance and butanol fermentation of Clostridium acetobutylicum from wheat straw hydrolysate by supplying sodium sulfide. Bioresour. Technol. 2015;198:77-86.

20. Guo ZP, Olsson L. Characterization and fermentation of side streams from sulfite pulping. Process Biochem. 2014;49:1231-1237.

21. Albuquerque TL, Gomes SDL, Jr JE, et al. Xylitol production from cashew apple bagasse by Kluyveromyces marxianus CCA510. Catal. Today. 2015;255(15):33-40.

22. Baer SH, Blaschek HP, Smith TL. Effect of Butanol Challenge and Temperature on Lipid Composition and Membrane Fluidity of Butanol-Tolerant Clostridium acetobutylicum. Appl. Environ. Microb. 1987;53(12):2854-2861.

23. Mussatto SI, Santos JC, Roberto IC. Effect of $\mathrm{pH}$ and activated charcoal adsorption on hemicellulosic hydrolysate detoxification for xylitol production. J. Chem. Technol. Biot.
2004;79:590-596.

24. Kundu C, Lee JW. Bioethanol production from detoxified hydrolysate and the characterization of oxalic acid pretreated Eucalyptus (Eucalyptus globulus) biomass. Ind. Crop. Prod. 2016;83:322-328.

25. Gao XF, Zhao H, Zhang GH, et al. Genome Shuffling of Clostridium acetobutylicum CICC 8012 for Improved Production of Acetone-Butanol-Ethanol (ABE). Curr. Microbiol. 2012;65:128-132.

26. Yerushalmi L, Volesky B, Leung WK, et al. Variations of Solvent Yield in Acetone-Butanol Fermentation. Eur. J. Appl. Microbiol. 1983;18:279-286.

27. Hezarjaribi M, Ardestani F, Ghorbani HR. Single Cell Protein Production by Saccharomyces cerevisiae Using an Optimized Culture Medium Composition in a Batch Submerged Bioprocess. Appl. Biochem. Biotech. 2016;179:1336-1345.

28. Rajagopalan G, Krishnan C. alpha-amylase production from catabolite derepressed Bacillus subtilis KCC103 utilizing sugarcane bagasse hydrolysate. Bioresour. Technol. 2008;99:3044-3050.

29. Maurelli L, Ionata E, La Cara F, et al. Chestnut Shell as Unexploited Source of Fermentable Sugars: Effect of Different Pretreatment Methods on Enzymatic Saccharification. Appl. Biochem. Biotech. 2012;170:1104-1118.

30. Castro E, Diaz MJ, Cara C, et al. Dilute acid pretreatment of rapeseed straw for fermentable sugar generation. Bioresour. Technol. 2011;102:1270-1276.

31. Naranjo JMD, Callejon MJJ, Vasquez MP, et al. Optimization of the enzymatic synthesis of structured triacylglycerols rich in docosahexaenoic acid at sn-2 position by acidolysis of Aurantiochytrium limacinum SR21 oil and caprylic acid using response surface methodology. J. Appl. Phycol. 2021;33(4): 2031-2045

32. Sepahi M, Norouzian D, Cohan RA, et al. Optimization of the Endotoxin Removal Performance of Solid-Phase Conjugated S3E3 Antimicrobial Peptide Using Response Surface Methodology. Int. J. Pept. Res. Ther. 2021;27:2029-2037.

33. Cai D, Zhang T, Zheng J, et al. Biobutanol from sweet sorghum bagasse hydrolysate by a hybrid pervaporation process. Bioresour. Technol. 2013;145:97-102.

34. Jonglertjunya W, Makkhanon W, Siwanta T, et al. Dilute Acid Hydrolysis of Sugarcane Bagasse for Butanol Fermentation. Chiang Mai J. Sci. 2014;41:60-70.

35. Luo W, Wang J, Liu X, et al. A facile and efficient pretreatment of corncob for bioproduction of butanol. Bioresour. Technol. 2013;140:86-89.

36. Karapatsia A, Pappas I, Penloglou G, et al. Optimization of Dilute Acid Pretreatment and Enzymatic Hydrolysis of Phalaris aquatica L. Lignocellulosic Biomass in Batch and Fed-Batch Processes. Bioenerg. Res. 2017;10:225-236.

37. Martinez A, Rodriguez ME, York SW, et al. Effects of $\mathrm{Ca}(\mathrm{OH})_{2}$ treatments ("overliming") on the composition and toxicity of bagasse hemicellulose hydrolysates. Biotechnol. Bioeng. 2000;69(5):526-536.

38. Converti A, Domínguez JM, Perego P, et al. Wood Hydrolysis and Hydrolyzate Detoxification for Subsequent Xylitol Production. Chem. Eng. Technol. 2000;23(11):1013-1020.

39. Qureshi N, Saha BC, Dien B, et al. Production of butanol (a 
biofuel) from agricultural residues Part I - Use of barley straw hydrolysate. Biomass Bioenerg. 2010;34(4):559-565.

40. Andary J, Maalouly J, Quaini R, et al. Application of 2D correlation spectroscopy on olive stones acid hydrolysates: effect of overliming. Chemometr. Intell. Lab. 2012;113(15):58-67.

41. Shukor H, Al-Shorgani NKN, Abdeshahian P, et al. Production of butanol by Clostridium saccharoperbutylacetonicum N1-4 from palm kernel cake in acetone-butanol-ethanol fermentation using an empirical model. Bioresour. Technol. 2014;170:565-573.

42. Ajao O, Le Hir M, Rahni $M$, et al. Concentration and Detoxification of Kraft Prehydrolysate by Combining
Nanofiltration with Flocculation. Ind. Eng. Chem. Res. 2015;54: 1113-1122.

43. Jeong SY, Trinh LTP, Lee HJ, et al. Improvement of the fermentability of oxalic acid hydrolysates by detoxification using electrodialysis and adsorption. Bioresour. Technol. 2014;152: 444-449.

44. Jin L, Zhang H, Chen LW, et al. Combined overexpression of genes involved in pentose phosphate pathway enables enhanced D-xylose utilization by Clostridium acetobutylicum. J. Biotechnol. 2014;173:7-9. 